Check for updates

Cite this: RSC Adv., 2019, 9, 12580

Received 17th January 2019

Accepted 11th April 2019

DOI: $10.1039 / c 9 r a 00428 a$

rsc.li/rsc-advances

\title{
Simple and efficient dual-wavelength spectroscopy for the determination of organic matter in sewage sludge from wastewater treatment
}

\begin{abstract}
Xiaojie Tu, ${ }^{a}$ Zhanbo Hu, (D) *b Xin-Sheng $\mathrm{Chai}^{\mathrm{c}}$ and Yuting Su ${ }^{\mathrm{b}}$
In this study, a dual-wavelength spectroscopic method for rapid determination of organic matter in sludge was developed. The contents of the organic matter were calculated by determining the consumption of potassium dichromate $\left(\mathrm{K}_{2} \mathrm{Cr}_{2} \mathrm{O}_{7}\right)$ based on the production of trivalent chromium ions $\left(\mathrm{Cr}^{3+}\right) . \mathrm{Cr}^{3+}$ could be determined by subtracting the absorption at $800 \mathrm{~nm}$ (spectral interference) from the absorption at $650 \mathrm{~nm}$ (only contributed by $\mathrm{Cr}^{3+}$ ). The results showed that the relative standard deviation in the test was less than $5 \%$. The same set of samples was used and when the content of organic matter was more than $150 \mathrm{~g} \mathrm{~kg}^{-1}$, the relative difference between the spectroscopic method and titration method was within $1 \%$. Furthermore, the method does not require calibration based on the standard samples. In conclusion, the present method is simple, reliable, accurate and suitable for application in mass testing for sludge samples.
\end{abstract}

\section{Introduction}

Sewage sludge is a sort of semi-solid slurry from wastewater treatment processes. ${ }^{1}$ Because of the rich contents of organic matter (OM) in such sludge (ranging from 40 to $60 \%$ ), ${ }^{2}$ it can be utilized as a fertilizer or soil conditioner for the growth of plants and soil improvement. ${ }^{3-6}$ Since the content of OM in sewage sludge is an important parameter for soil related sludge utilization, it is highly desired to have an efficient method for OM quantification in related research and applications.

Currently, the content of OM in a sludge sample is determined by either the Walkley-Black (WB) method (based on potassium dichromate oxidation) or the combustion method (determined by ignition of the samples at $550{ }^{\circ} \mathrm{C}$ ). ${ }^{7-10} \mathrm{In}$ the $\mathrm{WB}$ method, the organic matter reacts with an overdosed dichromate ion $\left(\mathrm{Cr}_{2} \mathrm{O}_{7}{ }^{2-}\right)$ to form $\mathrm{Cr}^{3+}$ in a sulfuric acid medium. ${ }^{11}$ The excessive amount of dichromate ions is then quantified by the titration with a ferrous sulfate standard solution, ${ }^{12}$ from which the content of $\mathrm{OM}$ in the sludge sample can be determined. Besides the complicity in preparing the standard ferrous sulfate solution, the titration procedure is also complicated and timeconsuming. The major problem in the combustion method is the interferences from some inorganic components, typically the carbonate and bicarbonate salts.

${ }^{a}$ College of Forestry, Guangxi University, Nanning, China

${ }^{b}$ School of Resources, Environment and Materials, Guangxi University, Nanning, China.E-mail: huzhanbo@gxu.edu.cn

${ }^{c}$ State Key Laboratory of Pulp and Paper Engineering, South China University of Technology, Guangzhou, China
Recently, a method combining Fourier-transform infrared photoacoustic (FTIR-PAS) and Raman spectroscopies has been proposed for the OM quantification. ${ }^{12}$ In this method, the soil samples were scanned by FTIR-PAS and Raman spectrometers in the range of $4000-400 \mathrm{~cm}^{-1}$ and $180-$ $3200 \mathrm{~cm}^{-1}$, respectively, from which the content of OM in the samples can be predicted based on a calibration model. Although the sample pretreatment in this non-destructive method is very simple, an exhausting measurements based on the above reference method for a set of training samples $(>30)$ is required in the model establishment. ${ }^{13}$ Moreover, besides the expensive cost in the instruments and their maintenance, the model will be no longer valid if the background of samples changes. ${ }^{14}$

According to WB method, the $\mathrm{Cr}^{3+}$ ions are the product from the reaction between the organic matter in soil and dichromate ions $\left(\mathrm{Cr}_{2} \mathrm{O}_{7}{ }^{2-}\right)$. Since $\mathrm{Cr}^{3+}$ ions have a color (dark green) in the visible wavelength range, they can be easily analyzed by visible spectroscopy according to Beer's law. However, it could be the major challenge to eliminate the spectral interference from other co-existing species in the above post-reaction medium.

In this work, we proposed a simple and efficient spectroscopic method for the determination of OM content in sludge samples, based on the dichromate oxidation. The major focuses were to find the suitable wavelength for the $\mathrm{Cr}^{3+}$ quantification and the method for correcting the effect of light scattering caused by the tiny particles (from soil) in the reaction medium. The performance of the method (e.g., the measurement precision and accuracy) was also evaluated. 


\section{Experimental}

\subsection{Materials}

All of these chemicals used in this study were analytical grade and provided by local chemical manufacturers, which included potassium dichromate (purity $>99.8 \%$ ), sulfuric acid (purity $>$ 98\%), phenanthroline (purity $>99.5 \%$ ), ferrisulphas (purity $>$ 99.5\%), quartz sand, potassium hydrogen phthalate (purity > 99.8\%). Distilled and deionized water used in all experiments was prepared by Ultra-pure Water Purifier (Barnstead Smart2Pure, Thermo Scientific, Waltham, MA).

The sludge samples were collected from a municipal wastewater treatment plant located in Nanning (Guangxi, China). Prior to analysis, the samples were air-dried, crushed at room temperature, and screened through a $0.25 \mathrm{~mm}$ mesh sieve for removing any plant roots and debris.

\subsection{Apparatus}

A Graphite dissociator (DigiPREP MS, SCP SCIENCE, CANADA), preheated to $180^{\circ} \mathrm{C}$, was employed for the digestion of sludge. A UV-Vis spectrophotometer (Shimadzu UV-1800, JAPAN) equipped with a $0.5 \mathrm{~cm}$ quartz cell was used for the measurements. Absorptive spectra of the solutions were recorded over the wavelength $200-800 \mathrm{~nm}$ at a scan speed of $2800 \mathrm{~nm} \min ^{-1}$ with the fixed width of slit $(1 \mathrm{~nm})$.

\subsection{Sample preparation and experimental procedures}

2.3.1 Preparation of the standard solution and samples. Digestion solution ( $\left.0.136 \mathrm{M} \mathrm{K}_{2} \mathrm{Cr}_{2} \mathrm{O}_{7}-\mathrm{H}_{2} \mathrm{SO}_{4}\right)$ : accurately weigh $20 \mathrm{~g}$ of $\mathrm{K}_{2} \mathrm{Cr}_{2} \mathrm{O}_{7}$ and dissolve it with distilled water in a $500 \mathrm{~mL}$ flask. Then, $400 \mathrm{~mL}$ of the $\mathrm{K}_{2} \mathrm{Cr}_{2} \mathrm{O}_{7}$ solution were placed in a $1 \mathrm{~L}$ beaker, followed by slowly adding the equal volume of concentrated $\mathrm{H}_{2} \mathrm{SO}_{4}$ into the solution and mixed well.

Accurately weigh $123.35,236.70,493.40$, and $740.10 \mathrm{~g}$ of potassium hydrogen phthalate, followed by mixing with the different amount of quartz sand to reach a total weight of $1000 \mathrm{~g}$ (the contents of OM in these samples were 100, 200, 400, and $600 \mathrm{~g} \mathrm{~kg}^{-1}$, respectively).

A $0.05 \mathrm{~g}$ of sample and $20 \mathrm{~mL}$ of digestion solution were added into a $50 \mathrm{~mL}$ PTFT digestion tube and blended well. After the graphite dissociator was preheated to $180{ }^{\circ} \mathrm{C}$, the digestion tube placed in and let the solution be boiled for $5 \mathrm{~min}$. Then the tube was taken out for cooling to the room temperature.

2.3.2 Sample measurement. The above resulting solution in the tube was spectroscopically measured and the absorbances at the visible wavelength range were recorded. The quartz sand from the above treatment was used as a blank in the measurement.

For a comparison, a series of parallel samples were digested and the resulting solution were also determined by a reference titration method, ${ }^{15}$ based on the following procedures: the solution in the digestion tube was completely transferred into the $250 \mathrm{~mL}$ conical flask (with 2-3 times' water washing) to keep the total volume of solution about $100 \mathrm{~mL}$. After add 3 drops of phenanthroline indicator, the solution was titrated by the ferrisulphas standard solution to the end-point color (brown reddish). The volume of the standard solution consumed at the end-point was recorded.

\section{Results and discussion}

\subsection{Spectral characteristics of $\mathrm{Cr}_{2} \mathrm{O}_{7}{ }^{2-}$ and $\mathrm{Cr}^{3+}$}

The present method is based on the reaction between the $\mathrm{C}$ of $\mathrm{OM}$ in sludge and potassium dichromate (overdosed), i.e.,

$$
\mathrm{Cr}_{2} \mathrm{O}_{7}^{2-}+\mathrm{C}+\mathrm{H}^{+} \rightarrow \mathrm{Cr}^{3+}+\mathrm{CO}_{2}+\mathrm{H}_{2} \mathrm{O}
$$

After the digestion reaction, some part of $\mathrm{Cr}_{2} \mathrm{O}_{7}{ }^{2-}$ is converted to $\mathrm{Cr}^{3+}$. Therefore, both $\mathrm{Cr}_{2} \mathrm{O}_{7}{ }^{2-}$ and $\mathrm{Cr}^{3+}$ ions present in the medium. Fig. 1 shows the spectra of $\mathrm{Cr}_{2} \mathrm{O}_{7}{ }^{2-}$ and $\mathrm{Cr}^{3+}$ in the solutions. It can be seen from the figure that the spectra of these two species are completely overlapped at the visible wavelengths below $650 \mathrm{~nm}$. However, the absorbance $(A)$ at the wavelength range between $650 \mathrm{~nm}$ and $800 \mathrm{~nm}$ is only contributed by $\mathrm{Cr}^{3+}$ (which has a maximum absorptivity at $605 \mathrm{~nm}$ ).

Fig. 2a shows the spectra of $\mathrm{Cr}^{3+}$ in the digested medium with different $\mathrm{OM}$ contents. Fig. $2 \mathrm{~b}$ shows the linear relationship between the spectral absorption at $650 \mathrm{~nm}\left(\right.$ for $\left.\mathrm{Cr}^{3+}\right)$ and the OM content in the solution, i.e., agreed to Beer's law. ${ }^{\mathbf{1 6}}$ Therefore, the content of $\mathrm{Cr}^{3+}$ (proportional to the OM content) in the digested medium can be simply determined by the spectroscopic measurement at $650 \mathrm{~nm}$ if there is no any spectral interference.

\subsection{Spectral interferences}

As noticed in Fig. 2a, there is a baseline shifting at $650 \mathrm{~nm}$ even for these artificial prepared sample (make up with quartz sand), which leads to an intercept in the absorbance calibration curve shown in Fig. 2b. The baseline shifting is mainly caused by the light scattering (due to the presence of tiny particles in the solutions), including refraction, reflection, diffraction and absorption, which weakens the transmitted light and increase the measured absorbance. ${ }^{17,18}$

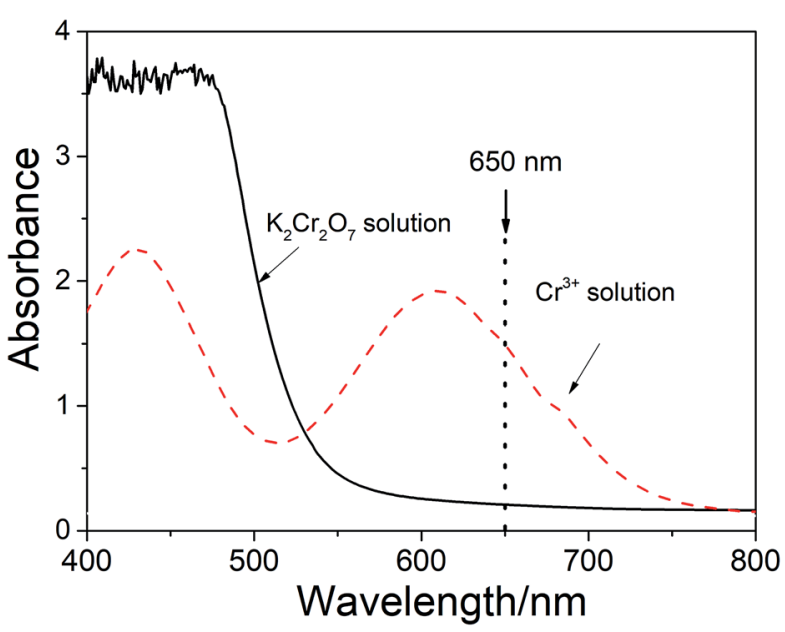

Fig. 1 Visible spectra of $\mathrm{Cr}_{2} \mathrm{O}_{7}^{2-}$ and $\mathrm{Cr}^{3+}$. 

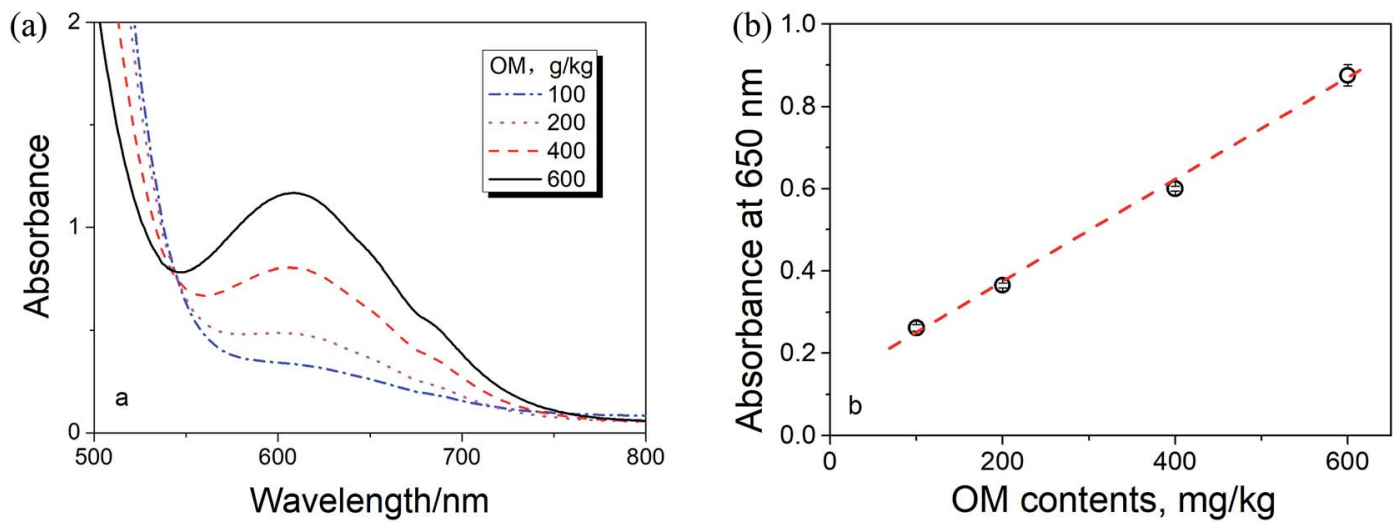

Fig. 2 (a) The spectra of $\mathrm{Cr}^{3+}$ and (b) the relationship between the absorption at $650 \mathrm{~nm}$ vs. the OM content in the samples.

To figure out this effect, we conducted the spectroscopic measurement on a quartz sand and several sludge samples with and without oxidation and their spectra are shown in Fig. 3. It is clear that the baseline shifting caused by the light scattering takes place in the entire visible wavelength range in both cases. No doubt, the above baseline shifting definitely affects the accuracy of the method based on the absorbance measurement at $605 \mathrm{~nm}$. Fortunately, because the effect of the shifting at $650 \mathrm{~nm}$ is very closed to that at $800 \mathrm{~nm}$, a wavelength without $\mathrm{Cr}^{3+}$ absorption (see Fig. 1 and 3a), we can easily minimize the spectral interference caused by the particles' light scattering by subtracting the absorbance at $800 \mathrm{~nm}$ (as the reference).

\subsection{Establishment of dual-wavelength spectrometric method}

According to Fig. 1, the absorbance at $650 \mathrm{~nm}$ is contributed by the absorbances caused by $\mathrm{Cr}^{3+}$ and particles' light scattering, i.e.,

$$
A_{650}=A_{\mathrm{cr}^{3+}, 650}+A_{\mathrm{ss}, 650}
$$

As shown in Fig. 3a, the absorbance of $650 \mathrm{~nm}$ is nearly close to that of $800 \mathrm{~nm}$, i.e.,

$$
A_{\mathrm{ss}, 650}=A_{800}
$$

Table 1 Absorptivity of $\mathrm{Cr}^{3+}$ at $650 \mathrm{~nm}$

\begin{tabular}{ll}
$\begin{array}{l}\text { Concentration } \\
\text { of } \mathrm{Cr}^{3+}, \mathrm{mol} \mathrm{L}^{-1}\end{array}$ & $\varepsilon_{\mathrm{Cr}^{3+}, 650}, \mathrm{~L} \mathrm{~mol}^{-1} \mathrm{~cm}^{-1}$ \\
\hline 0.8 & 1.67 \\
0.6 & 1.75 \\
0.4 & 1.82 \\
Average & 1.75 \\
\hline
\end{tabular}

Based on eqn (2) and Beer's law $(A=\varepsilon c)$, eqn (1) can be rewritten as

$$
A_{\mathrm{Cr}^{3+}, 650}=A_{650}-A_{800}=\varepsilon_{\mathrm{Cr}^{3+}, 650} c_{\mathrm{Cr}^{3+}}
$$

where $\varepsilon_{\mathrm{Cr}^{3+}, 650}$ is the absorptivity of $\mathrm{Cr}^{3+}$ at $650 \mathrm{~nm}$.

The absorptivity of $\mathrm{Cr}^{3+}$ at $650 \mathrm{~nm}$ can be obtained based on a set of standard solutions, which is 1.75 , an average value from the measurements with different concentration (as listed in Table 1).

Thus, the concentrations of $\mathrm{Cr}^{3+}$ in the reaction solution can be calculated by

$$
c_{\mathrm{Cr}^{3+}}=\frac{A_{650}-A_{800}}{\varepsilon_{\mathrm{Cr}^{3+}, 650}}
$$
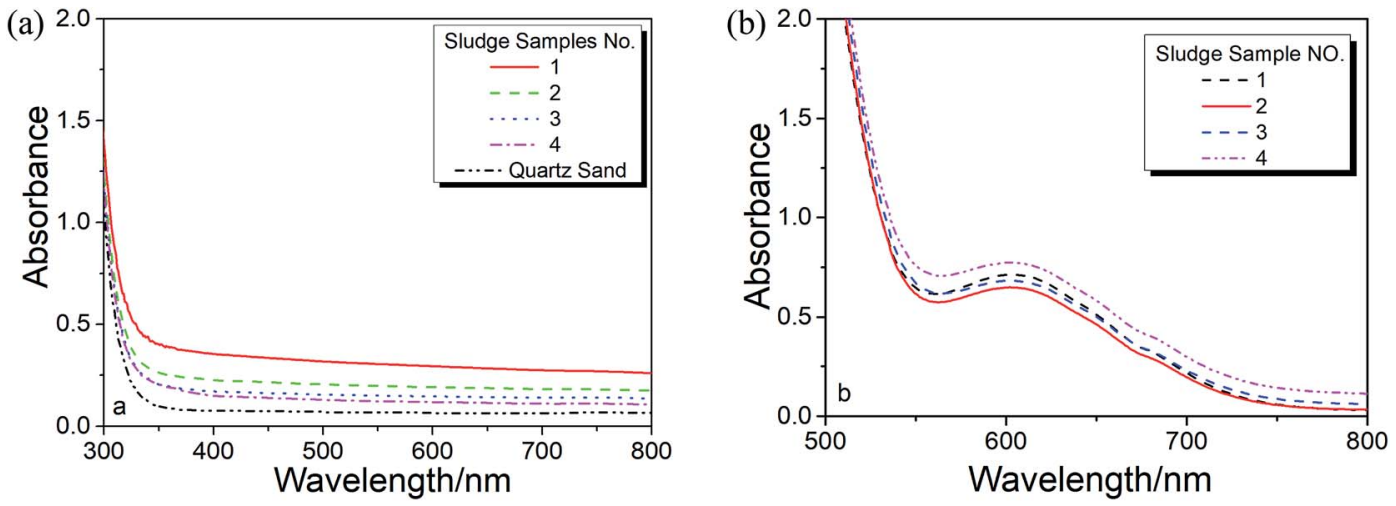

Fig. 3 Effect light scattering from (a) un-oxidized and (b) in this figure oxidized sewage sludge digested samples. 
Table 2 Repeatability of the method

\begin{tabular}{|c|c|c|c|c|c|c|}
\hline \multirow[b]{2}{*}{ Times } & \multicolumn{6}{|c|}{$\underline{\mathrm{OM}, \mathrm{g} \mathrm{kg}}$} \\
\hline & Sample 1 & Sample 2 & Sample 3 & Sample 4 & Sample 5 & Sample 6 \\
\hline 1 & 365 & 358 & 365 & 357 & 357 & 306 \\
\hline 2 & 372 & 355 & 348 & 364 & 360 & 313 \\
\hline 3 & 381 & 354 & 339 & 336 & 364 & 310 \\
\hline Average & 373 & 356 & 351 & 352 & 360 & 310 \\
\hline RSD\% & 2.14 & 0.54 & 3.69 & 4.06 & 1.11 & 1.13 \\
\hline
\end{tabular}

Table 3 Recoveries of the method

\begin{tabular}{llll}
\hline & \multicolumn{2}{l}{$\mathrm{OM}, \mathrm{g} \mathrm{kg}^{-1}$} & \\
\cline { 2 - 3 } Sample no. & Added & Measured & Recovered\% \\
\hline 1 & 100 & 112 & 112 \\
2 & 150 & 150 & 100 \\
3 & 200 & 201 & 100 \\
4 & 300 & 290 & 96.7 \\
5 & 400 & 375 & 93.7 \\
6 & 600 & 558 & 93.0 \\
\hline
\end{tabular}

from which the content of OM in the sludge sample can be calculated by

$$
\mathrm{OM}\left(\mathrm{g} \mathrm{kg}^{-1}\right)=\frac{\frac{A_{650}-A_{800}}{\varepsilon_{\mathrm{Cr}^{3+}, 650}} V \times 0.003 \times 1.724 \times 1.1}{m}
$$

where, $V$ is the volume of $\mathrm{K}_{2} \mathrm{Cr}_{2} \mathrm{O}_{7}, m$ is the sample quality, 0.003 is the molecular weight of $1 / 4$ carbon, $\varepsilon_{\mathrm{Cr}^{3+}, 650}$ is the absorptivity of $\mathrm{Cr}^{3+}, 1.724$ means that $1 \mathrm{~g}$ carbon equal to $1 \mathrm{~g}$ organic matter, and 1.1 is the oxidation correction constant.

\subsection{Method evaluation}

3.4.1 Precision of the method. The repeatability of the present method was determined by six different sludge samples. Table 2 lists the data from the repeatability test on the sample OM measurement by the present method. The results show that the relative standard deviation (RSD) is less than $5 \%$, indicating that the method has good precision.

3.4.2 Method validation. The recovery test was conducted to verify the accuracy of the method. The known amount of organic matter was added and then determined by the present method. As shown in Table 3, the present method has a good accuracy in the OM analysis (with the recoveries of 93-112\%). Therefore, it can meet the needs for the determination of OM in the sludge samples (covering a OM content range).

A comparison study was also conducted based on a set of real sludge samples from the wastewater treatment processes. The contents of OM in these samples were determined by both the present method and a reference titration method, and the results were shown in Table 4 . It can be seen from the table that the data obtained by these two methods have a good agreement. It further proves that the present method is justifiable to be used for the determination of OM content in the sludge samples, especially for the samples with high OM contents.

3.4.3 The limit of detection. To ensure the applicable range in the analysis of OM for the sludge sample, we investigated the detection sensitivity of the present method. Based on a set of standard samples, a calibration curve (net absorbance at $650 \mathrm{~nm} v s$. the standard content of organic matter) was plotted and it can be expressed as

$$
y=0.0013( \pm 0.0001) x+0.0511( \pm 0.0087)
$$

where $y$ represents the net absorbance at $650 \mathrm{~nm}, x$ represents the content of organic matter in standard samples. According to

\begin{tabular}{|c|c|c|c|c|c|c|c|}
\hline \multirow[b]{2}{*}{ Sample no. } & \multicolumn{2}{|l|}{$\mathrm{OM}, \mathrm{g} \mathrm{kg}^{-1}$} & \multirow[b]{2}{*}{$\mathrm{RD} \%$} & \multirow[b]{2}{*}{ Sample no. } & \multicolumn{2}{|l|}{$\mathrm{OM}, \mathrm{g} \mathrm{kg}^{-1}$} & \multirow[b]{2}{*}{$\mathrm{RD} \%$} \\
\hline & $\begin{array}{l}\text { Titration method } \\
(n=3)\end{array}$ & $\begin{array}{l}\text { Present method } \\
(n=3)\end{array}$ & & & $\begin{array}{l}\text { Titration method } \\
(n=3)\end{array}$ & $\begin{array}{l}\text { Present method } \\
(n=3)\end{array}$ & \\
\hline 1 & $34 \pm 3$ & $45 \pm 5$ & 13.9 & 11 & $217 \pm 8$ & $210 \pm 8$ & -1.64 \\
\hline 2 & $33 \pm 3$ & $50 \pm 4$ & 20.4 & 12 & $295 \pm 1$ & $290 \pm 1$ & -0.85 \\
\hline 3 & $46 \pm 3$ & $40 \pm 2$ & -6.98 & 13 & $327 \pm 8$ & $353 \pm 13$ & 3.82 \\
\hline 6 & $151 \pm 11$ & $149 \pm 4$ & -0.67 & 16 & $378 \pm 2$ & $375 \pm 8$ & -0.40 \\
\hline 7 & $172 \pm 1$ & $164 \pm 1$ & -2.38 & 17 & $429 \pm 4$ & $422 \pm 4$ & -0.82 \\
\hline 8 & $175 \pm 2$ & $167 \pm 2$ & -2.34 & 18 & $427 \pm 2$ & $420 \pm 2$ & -0.82 \\
\hline 9 & $179 \pm 1$ & $173 \pm 2$ & -1.70 & 19 & $814 \pm 10$ & $807 \pm 10$ & -0.43 \\
\hline 10 & $182 \pm 2$ & $175 \pm 1$ & -1.96 & 20 & $816 \pm 13$ & $801 \pm 3$ & -0.93 \\
\hline
\end{tabular}

Table 4 Method comparison for OM 
eqn (7), the limit of detection (LOD) of the method is $26.9 \mathrm{~g}$ $\mathrm{kg}^{-1}$. It indicates that the method is suitable to be used for the samples that OM is greater than $30 \mathrm{~g} \mathrm{~kg}^{-1}$, such as the sewage sludge from wastewater treatment plant.

$$
\mathrm{LOD}=\frac{a+3|\Delta a|}{S}
$$

where, $a, \Delta a$ and $s$ represent the uncertainty of the intercept and the slope in eqn (6), respectively.

\section{Conclusions}

A spectroscopic method for the determination of OM content in sludge samples has been developed. The results showed that the spectral interference caused by the particles' light scattering can be effectively minimized by a dual-wavelength measurement. Compared to the reference methods currently used in the determination of the OM content in sludge samples, the present method is much simple and efficient. Therefore, the proposed method can be used as a valuable tool to evaluate the OM content in sludge, especially for those to be converted to fertilizer or soil conditioner's applications.

\section{Conflicts of interest}

There are no conflicts to declare.

\section{Acknowledgements}

The authors acknowledge the financial supports from the Key Project of the Science and Technology Ministry of Nanning, China (Grant No. 20183045-2).

\section{References}

1 Q. Zhang, J. Hu, D. Lee, Y. Chang and Y. Lee, Bioresour. Technol., 2017, 243, 1159.

2 P. Theodoratos, A. Moirou, A. Xenidis and I. Paspaliaris, J. Hazard. Mater., 2000, 77, 177.

3 Q. H. Zhang, W. N. Yang, H. H. Ngo, W. S. Guo, P. K. Jin, M. Dzakpasu, S. J. Yang, Q. Wang, X. C. Wang and D. Ao, Environ. Int., 2016, 92-93, 11.

4 G. Yang, G. Zhang and H. Wang, Water Res., 2015, 78, 60.

5 B. O. Clarke and S. R. Smith, Environ. Int., 2011, 37, 226.

6 A. Navas, F. Bermúdez and J. Machín, Geoderma, 1998, 87, 123.

7 H. Zhong, H. Wang, X. Liu, C. Liu, G. Liu, Y. Tian, X. Feng and Y. Chen, Chemosphere, 2017, 180, 57.

8 D. Kulikowska, Waste Manage., 2016, 49, 196.

9 H. Liu, Sci. Total Environ., 2016, 566-567, 8.

10 X. Zhao, B. Li, J. Ni and D. Xie, J. Integr. Agric., 2016, 15, 232. 11 I. Raya-Moreno, R. Cañizares, X. Domene, V. Carabassa and J. M. Alcañiz, Sci. Total Environ., 2017, 598, 604.

12 Z. Xing, C. Du, K. Tian, F. Ma, Y. Shen and J. Zhou, Talanta, 2016, 158, 262.

13 R. A. V. Rossel and T. Behrens, Geoderma, 2010, 158, 46.

14 Y. Ogena, C. Neumann, S. Chabrillat, N. Goldshleger and E. B. Dor, Geoderma, 2018, 321, 100.

15 A. Walkley and I. A. Black, Soil Sci., 1934, 37, 29.

16 J. M. Parnis and K. B. Oldham, J. Photochem. Photobiol., A, 2013, 267, 6.

17 J. Wu, C. Ho, C. Huang, A. Srivastav, J. Tzeng and Y. Lin, Sensors, 2014, 14, 22670.

18 S. Fogelman, H. Zhao and M. Blumenstein, Anal. Bioanal. Chem., 2006, 386, 1773. 